http://dx.doi.org/10.18232/alhe.999

Artículos

\title{
Poblar el sitio de libres de Pedraza para obtener "utilidad a la agricultura, al público y al Estado", Gobernación de Santa Marta, Nueva Granada, 1790-1794
}

\section{Populate the site of free of Pedraza to obtain "utility to the agriculture, the public and the State", Governorate of Santa Marta, Nueva Granada, 1790-1794}

Hugues R. Sánchez ${ }^{1}$ * (D) 0000-0001-7056-8708

${ }^{1}$ Universidad del Valle, Cali, Colombia.

*Correspondencia: ahugues82@hotmail.com

Resumen. A partir de un proceso en el Archivo General de la Nación de Colombia, sobre la destrucción del sitio de Pedraza, se muestra la existencia de una política trazada desde Madrid y materializada en el virreinato de Nueva Granada que fomentaba la agregación de la población que, supuestamente, vivía de manera licenciosa en las orillas del río Magdalena, buscando convertirlos en labradores o colonos que debían producir granos y carnes para el abasto de la ciudad de Cartagena; conjunto de iniciativas que encajan en el fenómeno histórico denominado poblacionismo agrario ilustrado. Igualmente, se detallan las peripecias que enfrentó el encargado de la fundación del sitio el capitán a guerra Josef Torregrosa y se muestra la aparición de un lenguaje ilustrado que avalaba las iniciativas de los funcionarios con innovaciones conceptuales, buscando fortalecer la fundación de pueblos y la producción agropecuaria.

CÓMO CITAR: Sánchez, H. (2019). Poblar el sitio de libres de Pedraza para obtener "utilidad a la agricultura, al público y al Estado", Gobernación de Santa Marta, Nueva Granada, 1790-1794. America Latina en la Historia Económica, 26(3), e999. DOI: 10.18232/alhe.999 
Palabras clave: poblacionismo agrario; fisiocracia; productividad agropecuaria.

Abstract. From a process in the General Archive of the Nation of Colombia, regarding the destruction of Pedraza's place, this paper portraits the evidence of the existence of a policy drawn from Madrid and materialized in the Viceroyalty of Nueva Granada, which promoted the insertion of the population who, supposedly, lived in a licentious manner of Magdalena River, aiming to turn them into farmers or colonists who should produced grain and meat to supplied the city of Cartagena; this variety of initiatives fits in to historical phenomenon called enlightened agrarian population. Likewise, it explains in detail the struggles faced by Josef Torregosa, war captain, who was in charge for the foundation of the settlement and it shows the emergence of an illustrated language that endorsed the initiatives of officials with conceptual innovations, looking for strengthening town's foundation and agrarian production.

Key words: agrarian population; physiocracy; agricultural productivity.

JEL: N56; Q15; Q18; R11; R12.

Recibido: 1 de julio de 2018.

Aceptado: 8 de octubre de 2019.

Publicado: 03 de junio de 2019.

\section{INTRODUCGIÓN}

Para el siglo XVIII en el virreinato de Nueva Granada, gracias al fuerte mestizaje, aparecen en los términos de varias gobernaciones y ciudades numerosos pueblos y abundante población flotante que, a los ojos de los miembros de los cabildos de las ciudades neogranadinas y la burocracia real, no calificaban como aptos para ser considerados vecinos; por ello de manera displicente fueron llamados libres, libres de todos los colores o arrochelados (Herrera, 2002). Poco importaba a los cabildos locales el surgimiento de estos poblados ubicados, ordinariamente, en las márgenes de ríos, dentro de las haciendas, cerca de minas o a orillas de los caminos (Arcila y Gómez, 2009).

Con la llegada del virrey Sebastián de Eslava a la ciudad de Cartagena, en pleno ataque inglés en 1741, se activaron unas políticas destinadas a agregar en sitios específicos a esta población que, aparentemente, escapaba a toda forma de control social y político (Fals-Borda, 1979; Meisel, 1980; Sánchez, 2008; Tovar, 1980) 11 Para este virrey, las fundaciones se justificaban puesto que era necesario ajustar el modo de vivir de la población "libre de la Provincia de Cartagena, Santa Marta y márgenes del río Magdalena, pues divididas las familias en el dilatado espacio de cada parroquia formando sus casas en el monte y selva que les parecía más cómoda, carecían de todo pasto espiritual y de la subordinación al cura y a la justicia y así vivían tan licenciosamente que no había exceso que no cometieran" (Colmenares, 1989, p. 50).

\footnotetext{
${ }^{1}$ En la primera mitad del siglo xviII apareció en la provincia de Cartagena y Santa Marta una categoría jurisdiccional llamada sitio de libres, con la cual se designaba a un lugar que no era ni villa, ni ciudad o pueblo de indios y cuyos habitantes eran racialmente mezclados, los cuales, según un cronista de la época "se nombran libres por distinguirse de los indios tributarios” y de todos los colores por sus diversos linajes (Peredo, 1971, p. 137).
} 
Realmente los intereses de Eslava eran otros y más precisos, buscando anticipar otro posible ataque inglés como el sufrido en 1741, consideraba que, una vez agrupada esta población, dotándolos de tierras comunales lograría incrementar la producción agropecuaria, para así evitar el desabastecimiento de la ciudad de Cartagena y garantizar la presencia de milicianos dispuestos a defender la mencionada ciudad en tiempos de guerra $2^{2}$

Así, la fundación de pueblos o sitios estuvo en la agenda del primer virrey que llegó a Nueva Granada. Sabemos también que uno de los encargados de agregar y fundar sitios en las gobernaciones de Santa Marta y Cartagena fue el maestre de campo José Mier y Guerra, quien en el proceso de integración política y jurisdiccional de estos nuevos vasallos realizó cambios sustanciales en el estatus de los llamados libres, quienes ahora, al vivir congregados adquieren la calidad de vecinos, con la consecuente asignación de privilegios, derechos y deberes (Mora, 1993; Rojas, 2007; Sánchez, 2015).

Si bien el proceso de fundación de sitios promovido por el virrey Eslava y su sucesor Pizarro ha sido estudiado y analizado por varios historiadores, notamos que existen pocos estudios que analicen la forma como dicha política de reducción y agregación de pueblos se implementó a finales del siglo xviII, en un contexto donde las ideas fisiócratas, entre otras corrientes, estaban a la orden del día. En esta tónica, buscamos demostrar que las políticas de la monarquía rediseñaron -entre tantas cosas-, la forma de agregar a la población y el acceso a la propiedad comunal, subordinando los reformadores la fundación de sitios o pueblos al discurso ilustrado pregonado y aplicado especialmente por la burocracia de Carlos III, no sólo en América, sino también en la península ibérica (Windler, 1997).

Antes, es necesario mencionar algunos cambios llevados a cabo por la monarquía dentro del ámbito político en el mencionado periodo. Este fenómeno institucional, que la historiografía ha llamado reformismo borbónico, es visto como un conjunto de acciones que buscaba apuntalar en la América hispana una mayor extracción de excedentes, fueran estos monetarios o de materias primas (Lynch, 1991). En este sentido, la mayoría de estudiosos coincide en señalar que para el siglo XVIII la monarquía española se había apropiado de un conjunto amplio de doctrinas que hacían énfasis en la necesidad de propiciar el crecimiento económico a ambos lados del Atlántico, no sólo

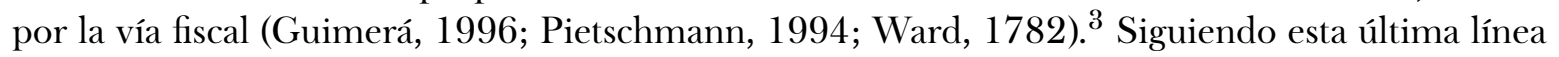
de análisis, varios historiadores se han dedicado a estudiar la acción reformista en diversas áreas de la América hispana, por ejemplo, Sánchez (2010, p. 332) señala que la monarquía católica, para el caso de Nueva España, a partir de 1750, desplegó "un volumen amplio y diversificado de iniciati-

\footnotetext{
${ }^{2} \mathrm{El}$ abastecimiento de granos y carnes de la ciudad de Cartagena siempre preocupó a los virreyes que pasaban por esta ciudad, la mayoría consideraba que la población libre de esta provincia debía dedicarse a la agricultura para así mantener abastecida a la tropa que habitaba la ciudad y se encontraba dispuesta a su defensa ante un nuevo ataque de los ingleses (Kuethe y Andrien, 2014; O’Byrne, 2013).

${ }^{3}$ La literatura histórica sobre el tema del surgimiento del llamado Estado moderno y el tema económico es abundante y escapa a los fines de este artículo (Epstein, 2009). En este sentido haremos referencia al Estado siguiendo la definición que de este se hace en los diccionarios de la época, por ejemplo, "se toma también por el País y dominio de un Rey, República o Señor de vasallos” (Diccionario de Autoridades, 1732, t. III). Mientras que sobre las acciones de gobierno llamadas razón de Estado se anota en el mismo diccionario que son las que se toman: "para la conservación, aumento y gloria del estado, y á que mira la política de los Príncipes. Ratio, vel causa status regni” (Real Academia, 2012, t. III).
} 
vas" que favorecieran el crecimiento económico 4 Mientras que para el Nuevo Reino de Granada, hace más de dos décadas, Anthony McFarlane (1997, p. 31) realizó el análisis más amplio sobre el impacto del reformismo en esta unidad administrativa, concentrándose en señalar que dichas medidas "buscaban reconstruir el dominio español", el cual habría de expresarse en una mayor captación de recursos fiscales y un incremento notorio del comercio. En esta misma vía, Pinto (2016, p. 72 ), luego de realizar un balance sobre los estudios sobre el reformismo borbónico en la Nueva Granada, señala que la mayoría de autores tenía "el pleno reconocimiento que la Corona implementó una serie de medidas encaminadas al incremento de la productividad de algunos sectores tales como la agricultura, el comercio, la minería y la producción de bienes con un alto nivel de consumo como lo fueron el tabaco y el aguardiente", entre otros aspectos económicos.

Por cuestiones de espacio, no nos detendremos a analizar de manera exhaustiva la historiografía sobre el fenómeno reformista, pero sí nos concentraremos en una de las aristas que atravesaban este conjunto de reformas, a saber, la necesidad de construir un mundo rural de campesinos productivos y adeptos a la monarquía, como también las políticas de incentivo a la producción agropecuaria y de fundación de pueblos. Efectivamente, para los funcionarios ilustrados era necesario cambiar de manera general las reglas de acceso a la tierra y reorganizar el espacio local-rural bajo jurisdicción de los cabildos, cuestión que pretendían con la expedición de la famosa Ley Agraria (Astigarraga y Usoz, 2007).

De manera general, este proceso encaja en una variante del pensamiento de los reformistas españoles, especialmente en lo que el historiador mexicano Covarrubias (2005, p. 208) llamó poblacionismo agrario: la necesidad de ubicar y dotar, a cierta población errante, de medios productivos, para convertirlos en hombres útiles que en los campos incrementaran la producción de granos y carnes, evitando así la escasez de alimentos y su acaparamiento por parte de hacendados. Así, fundar pueblos significaba, entre tantas cosas, expandir el privilegio de acceso a la tierra comunal y, a largo plazo, generar la aparición en el paisaje rural de una categoría de hombres industriosos, llamados en la época labradores o colonos (Canedo, 2015) $5^{5}$

El discurso ilustrado español potenciaba la idea de que los campos debían dejar de ser habitados por personas ociosas y si por el labrador propietario de una pequeña parcela, que con su producción se vinculaba a mercados comarcanos y o regionales (Astigarraga y Usoz, 2008; Caro, 2017). Estos consideraban que una forma de aumentar la productividad agropecuaria era evitando que los labradores pagaran por el arriendo de la tierra (Friera, 2007). Por ejemplo, el ilustrado Pablo de Olavide en su informe al consejo sobre la Ley Agraria de 1768 mencionaba que era necesario reglar el tema del subarriendo de tierras, "fijar el número de yuntas, o cabida de tierras equivalentes, de que no debe exceder ningún dueño labrador", como también "reducir a pueblo los cortijos" lo que redundaría en "la posible igualdad en el aprovechamiento de tierras a los vasallos [...] para arraigarlos y fomentar su industria" (Olavide, 1768, p. 359).

De la misma manera, Pedro Rodríguez (1764), quien, siguiendo a Mirabeau, en su respuesta fiscal sobre abolir la tasa y establecer el comercio de granos señalaba los caminos para obtener el crecimiento económico y los principales obstáculos que frenaban el desarrollo de España. Para el ilustrado por lo menos tres cuestiones debían intervenirse, primero, el tema de la concentración

\footnotetext{
${ }^{4}$ El estudio más sólido sobre el impacto del reformismo borbónico en las economías regionales en la América hispana y portuguesa, publicado recientemente, se concentra en señalar que "pese a las diferencias regionales a veces notables, la mayor parte del siglo xviI fue una etapa de crecimiento demográfico y económico bastante general en el espacio analizado" (Gelman, Llopis y Marichal, 2014, p. 525).

${ }^{5}$ Labrador, "el que personalmente trabaja y labra la tierra" (*Real Academia, 2012, t. Iv).
} 
de la propiedad, segundo, los obstáculos al libre comercio de granos (abastos) y, por último, la necesidad de vincular la población flotante o que viviera en vagancia en la producción agropecuaria (Guasti, 2013). Una década después, en 1774, en su discurso sobre la industria popular, el fiscal señalaba la importancia de expandir la frontera agrícola, advirtiendo que los desmontes de tierra y "formación de pueblos, que hizo el Cardenal Belluga, para dotar sus pías fundaciones, serán siempre un ejemplo del enlace, que tiene el bien del estado, con la distribución bien entendida de la limosna” (Rodríguez, 1774, p. 66).

Cuestión que a largo plazo debía traer un abaratamiento de los productos agrícolas y su circulación en los mercados gracias al libre comercio. Podríamos resumir el ideario ilustrado español en la necesidad de poblar para lograr el cultivo de más tierras y, de esa manera, fomentar el crecimiento demográfico, un circulo virtuoso que debía redundar en el crecimiento económico (Astigarraga, 2010; Perdices, 1993; Sánchez, 1988).

Tenemos entonces que este poblacionismo agrario ilustrado, cuya base era compartida por un conjunto extenso de corrientes económicas, entre las que se encontraba la fisiocracia, de manera general postulaba tres cuestiones importantes: $a$ ) una política de fundación de nuevas poblaciones o reconocimiento de estatus jurisdiccional a poblados que no lo tenían, $b$ ) la ejecución de normativas reformistas que se apoyaban en el expediente de la Ley Agraria y c) la dotación de calidades especiales al colono propietario, convirtiéndolo en el eje donde se debían materializar las transformaciones agrarias.

En efecto, estas ideas ilustradas atravesaron el Atlántico y empezaron a materializarse en el virreinato de Nueva Granada, confundiéndose con el primer proceso liderado por el virrey Eslava ${ }^{6}$ Por ejemplo, el virrey Guirior proponía una reforma agraria en el virreinato, esto porque, según él, la tierra se encontraba concentrada ya fuera en manos de la Iglesia o en privados que "no labran, ni para ello tienen facultades, ni permiten que otros las cultiven, quedándose yermas, sin que el común ni los particulares logren las ventajas que deberían", por lo que, como medida para remediar dicha situación planteaba que las tierras fueran repartidas para "beneficio del común" entre "poseedores laboriosos" para así lograr "una copiosa provisión de ganados, lanas, cueros y frutos, abundando las primeras materias por medio de la agricultura" (Colmenares, 1989, p. 299). Si bien el virrey consideraba la expropiación como medio para distribuir la tierra y elevar la productividad, esta medida radical nunca se llevó a cabo (Sánchez, 2016). Más bien, ante la existencia de tierras realengas, especialmente en las gobernaciones de Cartagena y Santa Marta, desde San Idelfonso se envió una cédula real el año de 1780 al virrey Manuel Antonio Flórez donde se le ordenaba que

Por lo respectivo a las tierras baldías que en el día pertenecen al real patrimonio y de consiguiente pueda este enajenarlas, he resuelto conformándome con lo expuesto por el fiscal de esta audiencia de cuyo dictamen sois vos mi virrey y lo fue vuestro antecesor que se os concedan graciosamente a los sujetos que las quisieren desmontar, sembrar y cultivar y mantenerlas siempre cultivadas con pastos o con siembras según su naturaleza excepto el tiempo necesario para su descanso, pena de que si no lo ejecutaren

\footnotetext{
${ }^{6}$ Para casos similares en otras regiones, especialmente en Veracruz, Nueva España, véase García (2015, pp. 295298).
} 
pierdan el derecho a ellas y se adjudiquen a otros, prefiriéndose al que las denunciare y con calidad también de que ninguno sujeto se concedan más porción de tierras que las que buenamente pudiere labrar ateniendo su caudal $[\ldots]]^{7}$

Pero fue el virrey Gil y Lemos, apoyándose en la anterior orden real, quien insistió en el “arreglo' 8 de la población, especialmente la que se encontraba orillas del río Magdalena. Señalaba este personaje que, a su paso por el canal del Dique en 1789, se le acercaron "de todas partes las gentes pidiendo se les proveyera de sacerdotes y reuniera en pueblos, a lo que inmediatamente proveí, según lo permitieron las circunstancias". Fue así como ordenó varias fundaciones, entre ellas, la fundación, entre Mahates y el sitio de Barranca, "forzoso paso para todo el interior del Reino", de "una población con cuarenta personas, reunidas en 12 familias, que voluntariamente quieren establecerse allí, a las que se les han distribuido tierras y asignado real y medio diarios, mientras se da la primera cosecha" (Colmenares, 1989, p. 18). Esta población llevaría el nombre de Pedraza y su fundación estaría a cargo del capitán a guerra Josef Torregrosa (véase mapa 1).

De esta forma, la población flotante que se encontraba en las riberas del río Magdalena fue nuevamente compelida a agregarse en sitios donde se les dotaba de institucionalidad y, para el caso analizado, de terrenos para sus casas y cultivos, como también de ermita para que recibieran los sacramentos católicos. En este sentido los virreyes que siguieron en gestión a Sebastián de Eslava continuaron con la agregación de población, compartiendo con el primero parte de las justificaciones, entre ellas las de abastecer la ciudad de Cartagena, pero, ahora, para finales del siglo XviI, la ideología que alimentaba la fundación de pueblos era arropada por el discurso fisiócrata, el bien público y la razón de Estado (Lempériere, 2014, p. 15). Este cambio en el lenguaje se mostraba más inclusivo y, a largo plazo, colocaba al colono en el centro de la política estatal, dándole la calidad de labrador.

Conviene señalar que interponerse en el universo político de las repúblicas establecidas a ambos lados del océano Atlántico fue una tarea difícil que precisó de consensos y negociaciones (Celaya, 2015; García, 1986). Por ello encontramos, para el caso del virreinato de Nueva Granada, que la intervención de la incipiente burocracia real fue relevante a la hora de fundar poblados y dotarlos de tierras comunales en las gobernaciones de Santa Marta y Cartagena. Fueron estos burócratas los que enfrentaron a las elites locales y, colocándose de parte de la población, en pleitos inacabables lograban vencer en derecho a quienes se oponían al reconocimiento de los sitios de libres (Garrido, 1993).

De manera general el poblacionismo agrario ilustrado avanzó cambiando el panorama jurisdiccional del área rural neogranadina, no sólo por la dotación de equipamiento institucional a la población libre, sino porque, a largo plazo, se dio un incremento notable de la producción agropecuaria, entre otras cuestiones.

Por otra parte, las innovaciones no sólo se quedaron en la inserción de la población en los mercados, sino que también se efectuó un cambio importante en el proceso de reglar en derecho la fundación de los sitios, nombrándoles autoridades (Bonil, 2011). Por ello, en los archivos encontramos numerosos expedientes que dan cuenta de las solicitudes y procesos de agregación de la población, mostrando una diversidad de factores que dan cuenta del origen de la población, sus

\footnotetext{
${ }^{7}$ Tierras del Magdalena, rollo 136, real cédula para las ventas y composiciones de realengos y administración de este ramo, San Yldefonso, 2 de agosto de 1777. Archivo General de la Nación (en adelante AGN).

${ }^{8}$ Arreglar debe leerse como sinónimo de poblar, agregar y agrupar.
} 


\section{MAPA 1. MAPA 1. PEDRAZA Y SITIOS CIRGUNVEGINOS UBICADOS A ORILLAS DEL RÍO MAGDALENA}

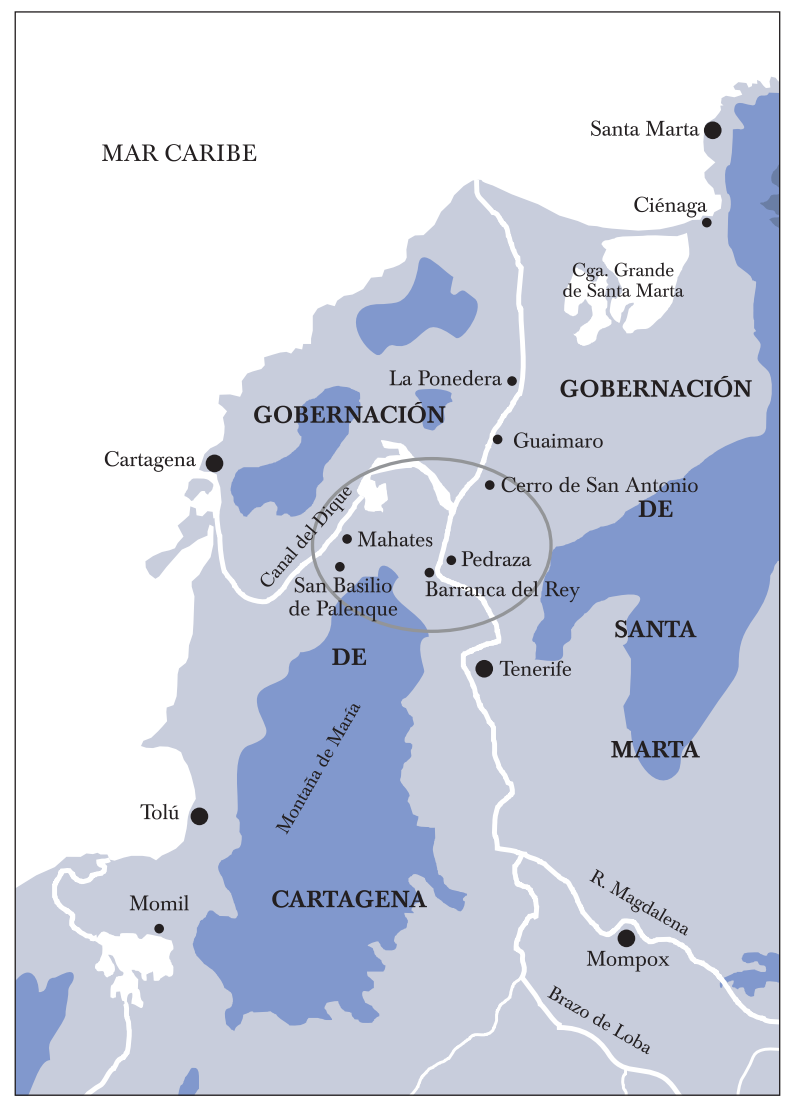

Fuente: elaboración propia con base en Herrera (2002).

moradores, la geografía y, en general, de sus aspiraciones en términos económicos, como también de las diversas vicisitudes que enfrentaron sus líderes o apoderados en su aspiración a que sus poblados fueran reconocidos institucionalmente, ser dotados de tierras comunales, elevados a la categoría de villa o parroquia (Bonnett, 2001; Guerrero, Pabón y Ferreira, 2014; Rodríguez, 2014). La cuestión es que en ocasiones estas fundaciones tuvieron oposición a nivel local, ya fuera porque jurisdiccionalmente menoscaban territorios de ciudades más antiguas o por la oposición de hacendados a cederles tierras de uso comunal (Herrera, 2009).

En el caso de Pedraza, las quejas de los vecinos del sitio de Cerro de San Antonio, población fundada en 1760 fueron escuchadas por el gobernador de Santa Marta don José de Astigarraga, quien ordenó la destrucción del sitio, levantándose un voluminoso proceso, en donde diversos actores se vieron involucrados, entre los que se encontraban un visitador general, el obispo de Santa Marta, el mencionado Torregrosa y varios fiscales, un procurador de número de la Audiencia de Santafé y, obviamente los vecinos de Cerro de San Antonio y Pedraza.

Así, en las siguientes páginas analizaremos el caso de fundación de un sitio de libres que se enmarca en la tendencia señalada del poblacionismo agrario y, en general, se inscribe en el proceso que buscaba integrar y dotar a los llamados libres de jurisdicción y privilegios corporativos, buscando 
transformarlos en labradores, acorde con el discurso fisiócrata. Daremos cuenta de las vicisitudes, problemas y oposición que tuvieron que enfrentar los encargados de materializar la política de fundación de pueblos y, también, de manera somera, mostraremos las particularidades del lenguaje político que potenciaba las acciones de los funcionarios reales.

\section{POBLAR PARA SERVIR A AMBAS MAJESTADES Y CAUSA PÚBLICA}

En el año de 1789 el visitador general de la gobernación de Santa Marta, Manuel Antonio Rubianes, por órdenes del virrey Gil y Lemos, ordenó la fundación del sitio de Pedraza, encargando de tal empresa al capitán aguerra del partido de Barranca del Rey Pablo Joseph Torregrosa, quien el 26 de marzo de 1791 señalaba que, a esa fecha, había "dexado a los colonos con sus trazas y familia en total amparo" en la nueva fundación. 9 Torregrosa de manera específica comentaba que había congregado "el número de 21 familias voluntarias, estas de distintos lugares" quienes, antes de su intervención vivían "unos y otros arrochelados en aquel desierto negados a la disciplina christiana, sirviendo de amparo a los perversos de una y otra Provincia y con el arreglo que habrá pudieran adelantarse en servicio de ambas Magestades y causa pública" 10

Mencionaba el capitán aguerra, ante rumores de quejas de los vecinos del cercano sitio de San Antonio, que no existía - para esa fecha- ningún problema jurisdiccional ya que la distancia que había de Pedraza al sitio de San Antonio era "de más de cuatro leguas". Consideraba entonces que ambas poblaciones podían "fomentarse en su cultivo, unos y otros" sin perjudicarse como ocurría con otros pueblos de la gobernación de Cartagena.

Pero, las cosas no salieron como las tenían presupuestadas Torregrosa y los vecinos de Pedraza, ya que los habitantes del sitio del Cerro de San Antonio se opusieron a la fundación y demolieron las casas y rozas de los pobladores del sitio, aduciendo que esta población menoscaba su jurisdicción. Respecto a la destrucción de las viviendas, señalaban los vecinos de Pedraza que el 16 de abril de 1791 habían llegado al sitio, en la mañana, el capitán aguerra de los sitios del Guaymaro y San Antonio, Lázaro de Robles, acompañado del alcalde pedáneo Manuel Bolívar y de otros vecinos, del cual destacaban a "un tal Yanuario Camacho", los cuales "entrando de ipso facto, con mucho gentío armado de hachas, machetes y fusiles, se ahorraron a nuestras casas y a pocos pasos la arruinaron y desmolieron' 11 sin importarles que sus mujeres estuvieran solas, ya que ellos "estaban en sus campos de labor, en las siembras de sus frutos", causando

tanto alboroto, algazara y gritería, junto con sus tiernos hijos, que asombrados lloraban amargamente, no siendo para menos la tribulación, pues hubo causa que de las paredes cayó una parte de ellas, sobre una en urgencia y por milagro de Dios, no le quitó la vida; pero en el lance murieron, algunas gallinas aplanadas en sus nidos de huevos y haciéndose pedazos algunos trastos, con los edificios, quando se desplomaban ${ }^{12}$

Ante los anteriores hechos los vecinos de Pedraza acudieron al capitán aguerra Josef Torregrosa solicitándole que informara y pidiera justicia a las autoridades radicadas en la ciudad de Santafé y denunciara lo que hicieron "en nuestras personas y bienes", cuestión que para ellos debía tener un

${ }^{9}$ Poblaciones SC 46, 6, D. 1, Representación que los vecinos de Pedraza hicieron a Pablo José Torregrosa para la fundación del sitio, 1791. AGN.

${ }^{10}$ Poblaciones SC 46, 6, D. 1, Representación. AGN.

${ }^{11}$ Poblaciones SC 46, 6, D. 1, Representación. AGN.

${ }^{12}$ Poblaciones SC 46, 6, D. 1, Representación. AGN. 
castigo ejemplar, porque "recae conforme y para castigo de un delito de igual circunstancias": 13 Lo cierto es que las cosas no quedaron en la impunidad, desde la Audiencia de Santafé los jueces dictaminaron que las personas que habían participado en los actos de desalojo debían pagar el valor de los daños causados, especialmente el gobernador Astigarraga, funcionario que había dado la orden de destrucción.

Encontramos que una vez la querella de los vecinos de Pedraza llegó a la ciudad de Santafé se activaron los mecanismos institucionales para defender los derechos que les habían sido vulnerados; en un primer momento los vecinos informaron al virrey sobre las "angustias impensadas" que habían sufrido y agradecían que "pueda con su notoria piedad y justificación declararnos pobladores del dicho paraje y dispensarnos las gracias y mercedes, que a bien tenga penando a los falsos informantes del sitio de San Antonio, no sólo en la reposición de nuestras casas, y la hermita, sino también en los demás quebrantos y perjuicios". 14

Una vez recibida la petición se procedió a instruir a un fiscal para que indagara sobre el caso, el cual a partir de julio de 1791 solicitó varios informes a los funcionarios implicados en el conflicto. Por esta vía nos enteramos sobre cómo fue el proceso de fundación del sitio. Al respecto, Torregrosa informaba que la idea de poblar Pedraza se originó a partir de que el obispo de Santa Marta Anselmo Joseph de Fraga, quien había pasado por el área a su regreso de la ciudad de Cartagena después de su consagración alentó a varios pobladores ubicados a orillas del Magdalena "para que procurásemos vivir en Dios, reuniéndonos y en tal caso, nos patrocinaría, mandando eclesiástico que nos administrase y facilitaría las luces correspondientes, de los respectivos superiores y como todos deseábamos, esta ocasión, nos ofrecimos prontos, a su cumplimiento".15

El obispo Anselmo Josef de Fraga señaló su preocupación porque en aquellos lugares vivieran las familias separadas y dispersas sin "el consuelo del pasto espiritual, ni quien los gobierne inmediatamente en lo temporal" y como había observado la existencia de terrenos que ofrecían "las más bellas proposiciones para hacer fundación a donde se forme pueblo" los incitó a agregarse para que tuvieran "la fortuna de tener arbitrio su juventud y que desde la primera edad se le acostumbre al trabaxo y cultivo de sus campos y que se libre conocida utilidad a la religión, al público y al estado" 16 Por todo lo anterior, valiéndose de sus potestades vio conveniente arreglar dicho desorden y por ello solicitó que la población dispersa se redujera "a población". Concluía el obispo, señalando que estaba al corriente de la "christiana conducta del capitán aguerra de la Barranca del Rey don Pablo Torregrosa de su actividad y celo de servicio de ambas Magestades”, como también de que a este se le habían dado facultades para realizar la fundación apoyándose en las "leyes reales [...] el título 5, libro 4 de la Recopilación de Yndias y en el título 7 del mismo libro" 17

La petición del obispo fue avalada, como ya vimos, por el visitador de la provincia de Santa Marta, Manuel Antonio Rubianes, quien autorizó al capitán del partido de Barranca del Rey en octubre de 1789 para que realizara la fundación de Pedraza. Este último, citando al obispo, autorizó el 24 de noviembre de 1790 la realización de la fundación de Pedraza. Rubianes enunciaba que por instrucciones del obispo y puesto que él tenía comisión por parte del virrey decidió encomendar a Pablo José Torregrosa para que "conforme a las leyes de los títulos 5 y 7 del libro 4

\footnotetext{
${ }^{13}$ Poblaciones SC 46, 6, D. 1, Representación. AGN.

${ }^{14}$ Poblaciones SC 46, 6, D. 1, Representación. AGN.

${ }^{15}$ Poblaciones SC 46, 6, D. 1, Representación. AGN.

${ }^{16}$ Poblaciones SC 46, 6, D. 1, Representación. AGN.

${ }^{17}$ Poblaciones SC 46, 6, D. 1, Representación. AGN.
} 
de los municipios que hablan de la materia, tratase de hacer la población de Pedraza dando juntamente parte de todo a vuestra Excelencia lo que también hizo el referido Torregrosa ${ }^{18}$ [por ser un funcionario] celoso y amante del bien público" que sólo buscaba que estos pobladores pudieran "vivir en sociedad", acatando y buscando siempre el "servicio del público y del Rey".

Una vez notificado Torregrosa de la comisión de fundación del sitio, informaba que se había encargado de cumplir la orden "válido de las facultades" y feliz "de alcanzar tan dichoso fin y más si la benignidad de vuestra Excelencia con su protección me autoriza para el intento”. Así, la empresa pobladora continuó y el 11 de enero de 1791 el capitán aguerra realizó un padrón de los vecinos que se asentarían en el sitio de Nuestra Señora de Santa Ana de Pedraza, señalando que contaba con 21 familias y cerca de 600 personas. Estos vecinos, dirigidos y financiados por Torregrosa habían abierto "el campo" y "delineando la plaza y calles" y construido la iglesia para la "celebración de oficios divinos", por ello expresaban su sentimiento de felicidad por permitírseles "reunirse y gozar pacíficos de las libertades, excepciones y privilegios". Igualmente, reconocían tener "nuestros crecidos campos de rozas, como es notorio, que todos los tenemos para asegurar el pan de cada día" y haber reedificado "nuestra hermita, ayudados del buen deseo de vuestra merced, que nos administraba graciosamente, con lo correspondiente para el sustento, como también con toda la palma que se necesitó para su cubierta"19

Por otro lado, el visitador general agregaba que cuando se reunió con el gobernador José de Astigarraga y este le notificó sobre su "resentimiento o extrañeza" por no habérsele informado del proceso de fundación se sintió extrañado, ya que él no buscaba con este acto perjudicar "la paz y tranquilidad del público". Por ello se mostraba asombrado que el gobernador, causando "dolor en su corazón”, hubiera ordenado al capitán aguerra del sitio del Guaymaro y San Antonio don Lázaro de Robles, pasase "a la recién nacida población, y demoliese y arrasase las casas enteramente" 20 Rubianes insistía en que nunca quiso "despojar al gobernador de Santa Marta de sus regalías, y vicepatronato real" al aprobar la fundación y mucho menos ir contra las leyes con procedimiento "tan extraños e irregulares", sobre todo porque el juez poblador de Barranca del Rey José Torregrosa ya había parado el proceso a la espera de una orden superior y, en vez de eso, se ordenó la destrucción del pueblo. Por ello creía que la acción del gobernador Astigarraga había sido "precipitada” y causaba "en aquellas gentes dispersas, el odio y aversión a toda reunión y sociedad", pero sobre todo "un daño particular a la religión y al Estado, que se intentarán en que vivan los hombres sujetos a la disciplina cristiana, y civil" 21

En tanto, el fiscal de la audiencia de apellido Berrio, una vez que recibió los primeros informes reprocha la acción del gobernador y considera que este debió respetar las órdenes del obispo y del visitador los cuales buscaban subsanar necesidades en la población de tipo espiritual y política. Para el fiscal, al autorizar Astigarraga a Lázaro Robles para que fuese a destruir aquella población, violaba el derecho de gentes y lo que preveían las leyes de Indias en dichas situaciones. Igual consideraba que el gobernador de Santa Marta hizo bien en reclamar y sustentar su regalía, pero no acertó en las órdenes que dio para que se destruyera el poblado. Hecho -para él- inhumano, lejano de todo buen gobierno y de las nociones del derecho público, más cuando la orden se ejecutó sin ninguna cautela y moderación, al no dar a los habitantes del sitio tiempo para que buscaran

${ }^{18}$ Poblaciones SC 46, 6, D. 1, Representación. AGN.

${ }^{19}$ Poblaciones SC 46, 6, D. 1, Representación. AGN.

${ }^{20}$ Poblaciones SC 46, 6, D. 1, Representación. AGN.

${ }^{21}$ Poblaciones SC 46, 6, D. 1, Representación. AGN. 
donde vivir y llevar sus familias a buscar amparo. Como vemos, el fiscal prevenía en su discurso el abuso de autoridad, precisando que a pesar de tener un funcionario jurisdicción debía obrar con cautela y no tomar acciones violentas, ya que a los vasallos del rey ahora los amparaba el derecho público que entraba a prevenir los desmanes de los funcionarios.

Fue así como el gobernador Astigarraga fue condenado el 2 de diciembre de 1791 por su decisión precipitada y “contraria a las leyes de la humanidad”, ya que debía primero consultar al superior gobierno "si acaso quería desagraviar sus facultades, que imaginaba usurpadas por aquel visitador, [en contra de] un gran bien tanto en lo moral, como en lo político" 22 En suma, para el fiscal el gobernador no debió proceder "asentadamente en la defensa de la regalía que goza como vicepatrón para formalizar población”, por lo que sentenciaba que debía reintegrarse a los vecinos de Pedraza "al estado en que se hallaban quando don Lázaro Robles llegó a ocurrirles en sus habitaciones" ${ }^{23}$ Lo anterior sirvió para que Torregrosa fuera autorizado para que emprendiera nuevamente la empresa pobladora y se encargara de conducir de nuevo a los vecinos "al antiguo sitio en que se hallaban para que de nuevo pueblen, auxiliándolos como en el primer estado lo verifica".

Para terminar, el fiscal encargado de lo civil el día 3 de agosto de $1792^{24}$ señalaba que era merecido que Pedraza, al igual que otras poblaciones tuviera "tan singular protección de su Magestad", por lo que recomendaba que no se obstruyeran las acciones que realizaba Torregrosa por los vecinos de San Antonio y que "se cuide y cele, el que los vecinos de ese sitio no perjudiquen, ni molesten a los pobladores, y antes bien lo auxilien en quanto sea posible para que florezca entre ellos la agricultura y abundancia como es de desearse" 25

De las anteriores líneas podemos sacar algunas conclusiones: la primera es que todos coincidían en que el gobernador Astigarraga no debió destruir el sitio, aun cuando según su concepto, se le estuviera rebajando su jurisdicción. El lenguaje utilizado por los denunciantes colocaba a este funcionario como un ser amoral que atacaba el nervio central de una política de buen gobierno que buscaba congregar almas dispersas y llevarlas a vivir en sociedad, en política, donde servirían a dios y al rey. Con sus actos Astigarraga iba contra la religión, la utilidad del público y el Estado, es decir, minaba principios ilustrados ahora básicos de la convivencia en sociedad y, por tanto, del buen gobierno.

\section{UN GOBERNADOR Y UN PROCURADOR DEL NÚMERO DEFIENDEN LOS DERECHOS JURISDICCIONALES DEL SITIO de Cerro de San Antonio}

Obviamente la decisión del fiscal fue apelada por el gobernador Astigarraga, mientras que los vecinos del sitio de San Antonio de Buenavista autorizaron a Januario Camacho para que a nombre del común del vecindario otorgara poder a un procurador de número de la Audiencia de Santafé para que los amparara. En dicho documento se aseguraba que ellos, los vecinos de Cerro de San Antonio, habían notificado al visitador Manuel Antonio Rubianes de su oposición a que se fundara a menos de tres leguas del sitio, cuestión que también informaron a Torregrosa para que suspendiera el proceso "por los perjuicios que se seguían a la parroquia principal de San Antonio"

\footnotetext{
${ }^{22}$ Poblaciones SC 46, 6, D. 1, Representación. AGN.

${ }^{23}$ Poblaciones SC 46, 6, D. 1, Representación. AGN.

${ }^{24}$ Poblaciones SC 46, 6, D. 1, Representación. AGN.

${ }^{25}$ Poblaciones SC 46, 6, D. 1, Representación. AGN.
} 
y por el "desmembro de sus vecinos" y, sobre todo, porque las tierras adjudicadas estaban en su jurisdicción lo que "daría ocasión para que con la estrecha vecindad se introdujesen los de las unas en otras se fomentarán los pleitos y perturbaría la paz que hasta ahora han gozado"26

En esta línea, el gobernador informaba que había consultado a Lázaro Robles, quien le señaló que no fue escuchado ni informado por el visitador y mucho menos por Torregrosa en el tema de la fundación. Insistía el gobernador que había procedido a hablar con el visitador para señalarle que este se excedía al ordenar fundar la población y especialmente violentaba "las leyes 1, título 3 y 2, título 6, libro 1 de Yndias" que reglaban la fundación de sitios y la construcción de iglesia. Por ello -aducía Astigarraga-, se vio en la necesidad de mandar a demoler el poblado "reduciendo todo al estado que antes tenía". Además, el gobernador consideraba que la nueva fundación invadía la jurisdicción de San Antonio, como también que los vecinos de Pedraza no tenían la suficiente capacidad económica para sostener una parroquia, por ello solicitaba se les diera respuesta a varias preguntas que a él le parecían importantes

sí convendrá que se erija parroquia en esta, dividiéndose el vecindario de San Antonio, quales son las razones de necesidad o utilidad que de ella resultaran, que vecinos son los que solicitan esta nueva fundación y si por sí podrán mantener cura, o si convendrá el que en aquel paraje se ponga un teniente cura a costa del de San Antonio, qué número de vecinos comprende Pedraza y si tanto estos como los de San Antonio hecha la división les quedarán tierras para criar ganados 27

En su defensa, Astigarraga anotaba que había intentado con el visitador una conferencia verbal para informarle que se había excedido mandando erigir "una parroquia sin que haya precedido justificación e informe de las causas de necesidad y utilidad que de ella se seguía” y, sobre todo, que alcanzó a señalarle que violaba las facultades que le concedía la ley 40, título 6, libro 1 de Yndias, a saber, que se debía contar para el proceso con su consentimiento y por ello consideraba que la comisión dada a Torregrosa iba "en perjuicio de las regalías del vice-real patronato" que él ejercía en la provincia de Santa Marta. Al tema de la construcción de la iglesia Astigarraga dedicó varias líneas, intentando sostener que los habitantes del sitio de Pedraza no tenían la capacidad para erigir una nueva iglesia o parroquia y mantener a un cura.

En el pleito también participó el procurador del número de la Real Audiencia Clemente Robayo, quien asumió como apoderado de los vecinos del sitio de San Antonio el 10 de diciembre de 1791. Para este funcionario el conflicto derivaba del hecho que el sitio de Pedraza se hubiera establecido en tierras del vecindario que él representaba, no sin antes criminalizar a los vecinos de Pedraza a los que tildaba de vagos y facinerosos, por lo que justificaba la acciones en su contra. Para Robayo la erección de Pedraza se realizó en terrenos "perteneciente a mis partes", lo que consideraba les era de "grave perjuicio y daña directamente a sus derechos" 28

En tanto, el gobernador Astigarraga volvió a escribir al fiscal, mostrándose contrario al decreto emitido por este el 2 de diciembre de 1791 donde se le condenaba a pagar los gastos de los bohíos y sementeras destruidas. Antes, para potenciar sus argumentos, procedió a criminalizar a los vecinos de Pedraza, señalando que allí vivían "algunas familias vagabundas y mal entretenidas que ni la justicia las ha podido reducir a vivir en poblado”. Luego volvía a su argumentación central,

${ }^{26}$ Poblaciones SC 46, 6, D. 1, Representación. AGN.

${ }^{27}$ Poblaciones SC 46, 6, D. 1, Representación. AGN.

${ }^{28}$ Poblaciones SC 46, 6, D. 1, Representación. AGN. 
dicha fundación se pretendió erigir en parroquia sin justificación previa, ni consentimiento del vicerreal patronato en perjuicio de los vecinos y sitio de San Antonio, el cual superaba a Pedraza en población "como que ascienden al número de más de 1600 personas de que se compone aquel vecindario 29

Insistía en que las tierras donde se había fundado Pedraza eran propias de los vecinos de San Antonio quienes por no tener suficientes cuando fue erigida parroquia decidieron comprarlas a "su Magestad, para aumento y extensión de su ganado, y labranza". Estas no fueron suficientes por lo que se vieron obligados a arrendar en 100 pesos las llamadas tierras de El Juncal al marqués de Torrehoyos. En su criterio no era pertinente quitar tierras a unos vecinos ya asentados para dárselas a otros en un proyecto de poblamiento incierto como el de Pedraza, ya que se estaría causando "un notorio perjuicio y agravio del sitio de San Antonio fundación antigua y una de las más útiles para el abastecimiento de esta plaza y la de Cartagena”, condenándola a su desolación. Intentaba sustentar sus argumentos señalando que los vecinos de Pedraza tenían poca producción ya que el territorio donde se instaló la población no tenía "más ancho que un quarto de legua" lo cual era pequeño "para más de 22 haciendas que tienen los habitantes del referido sitio, sin contar ni incluir el resto del ganado de los otros que no alcanzan a formar hato".

En general, para el gobernador Astigarraga la fundación de Pedraza no obedecía a un sincero acto de servicio por parte de Torregrosa, sino que lo motivaba el control de terrenos aptos para la cría de ganados ubicados en las orillas del río Magdalena. Calculaba el gobernador que cada año cerca de 6000 reses que provenían de la gobernación de Santa Marta y eran llevadas al abasto de la ciudad de Cartagena tenían "su pastadero en aquellas tierras por la comodidad del proporcionado embalse del río Magdalena que no en todas partes puede lograrse”. Para él, Torregrosa sabía de esto y por ello buscaba controlar terrenos donde los ganados se alimentaran en su viaje a Cartagena 30 Más adelante, dejando a un lado la moderación en la escritura arremetía de manera directa contra Torregrosa, al que acusaba de tener intereses concretos en la fundación de Pedraza, ya que -según él- esta empresa le garantizaría tierras para que pastaran sus ganados y "la gran porción de mulas que posee para el tráfico de Cartagena a Barranca”, adquirir "título de juez de aquella fundación” y hacer que se nombrara a su hermano "de cura de ella", aunque fuese gravando a la Real Hacienda con la creación de otro curato. Intereses que, según el gobernador, el Torregrosa disfrazaba "con apariencia de santos fines", por ello su actuar subrepticio para proceder a violar "el vice-patrono real" 31

Al final, con esas razones esgrimidas, Astigarraga solicitaba que se suspendiera la "superior providencia" que lo condenaba "en los costos, costas y prejuicios con las demás penas establecidas por reales disposiciones", sobre todo porque Pedraza se fundaba en "la provincia de mi mando, según las leyes de estos Reynos". A pesar de todos estos argumentos la sanción se mantuvo y sus argumentos no fueron tenidos en cuenta.

\footnotetext{
${ }^{29}$ Poblaciones SC 46, 6, D. 1, Representación. AGN.

${ }^{30}$ Astigarraga anotaba también que la fundación afectaría al pueblo de indios Chimilas de Guaquirí, los cuales estaban recién pacificados, intuyendo que los ganados de los vecinos de Pedraza destruirían sus sembrados de maíz, obligándolos a desertar de la población.

${ }^{31}$ Poblaciones SC 46, 6, D. 1, Representación. AGN.
} 


\section{Poblar PARA FORTALECER LA CLASE DE LOS COLONOS}

De manera tangencial José Torregrosa definió a los vecinos de Pedraza como un grupo al que denominó la clase de los colonos; de allí que fundar y poblar, ahora, era potenciar la aparición del labrador acomodado, con derechos de propiedad sobre una pequeña extensión de terreno, desde la cual aportaría al crecimiento económico (Andreucci, 2011, Usoz, 2008). Por ello, las fundaciones que se realizaron a finales del siglo Xviı en las orillas del río Magdalena tenían ese fin: poblar para producir alimentos que debían llevarse, en este caso, a la ciudad de Cartagena. Las políticas trazadas y aplicadas se debían concretizar en un sujeto o clase, la del colono 32 pero también debemos percibir que este concepto aludía a privilegios estamentales o, de clase, como se refería el capitán aguerra. Ahora, el poblador no sólo ganaba integración con el título de vecino del sitio, sino que también adquiría una adscripción económica que automáticamente elevaba la calidad de los labradores, dándole una virtud cívica.

Es posible encarnar al labrador o colono que habitaba el sitio de Pedraza, gracias a los inventarios que se realizaron a partir de los daños causados por los vecinos de Cerro de San Antonio. Tres inventarios dan cuenta de la dimensión productiva y el entorno material de los labradores (véase cuadro 1).

Tenemos entonces que, por ejemplo, la propiedad de Vicente Muñoz estaba dedicada a la cría de cerdos, gallinas y maíz a pequeña escala. A diferencia de esta, la propiedad de Juan Gregorio Meza tenía una casa aperada y no un simple rancho - de allí la diferencia de precios- y tenía la misma orientación económica. Por su parte, la propiedad de Victorino Josef Artaona tenía una orientación hacia la cría de ganado vacuno y más herramientas y enseres.

De manera general, advertimos que la producción de estos labradores era pequeña y sus bienes se componían de casa de palma y guaduas con su ajuar y contigua a esta se encontraban corrales para los animales que criaban, entre los que se hallaban cerdos, burros, pollinos y ganado vacuno. También sembraban maíz, yuca y ñame y criaban algunas gallinas y palomas. Pocos contaban con herramientas, sólo Juan Gregorio Meza que perdió un hacha valorada en un peso y ocho reales. De los trece inventarios, como ya señalamos, sobresale el de Victorino Josef Artaona quien tenía una casa valorada en 20 pesos, dos catres para dormir, tinajas para guardar semillas de maíz y dos piraguas para transportarse, 20 cabezas de ganado vacuno y dos cabuyas de maíz y yuca. Artaona parecía ser el más próspero de los habitantes de Pedraza. Por otro lado, se nota cierta especialidad en la cría de los cerdos y de gallinas ponedoras para la venta de huevos y en el cultivo de maíz y yuca; pequeña producción, que, no obstante, se vinculaba a los mercados comarcanos y que, posiblemente, terminaba alimentando a los habitantes de la ciudad de Cartagena.

Tras el proceso de refundación de Pedraza, el virrey ordenó a Torregrosa proseguir con sus acciones y que procurara "unir aquellos vecinos que a causa de la destrucción de su poblado estén dispersos, procurando conducirlos al antiguo sitio en que se hallaban, para que de nuevo pueblen" 33 Inmediatamente este dio inicio al proceso de refundación de Pedraza, por ello procedió a delimitar su plaza y calles y reedificar doce bohíos de igual número de familias que pudo reunir nuevamente ${ }^{34}$ levantó capilla para celebrar los oficios divinos, considerando que esto animaría a los pobladores ya inscritos y que se sumaran otros con ganas de convertirse en "la clase de colonos".

\footnotetext{
32 “Colono. s. m. El labrador que cultiva y labra alguna tierra por arrendamiento" (Diccionario de Autoridades, 1729, t. II).

${ }^{33}$ Poblaciones SC 46, 6, D. 1, Representación. AGN.

${ }^{34}$ Poblaciones SC 46, 6, D. 1, Representación. AGN.
} 


\section{CUADRO 1. INVENTARIOS DE DAÑOS CAUSADOS A VECINOS POR LA FUNDACIÓN DEL SITIO DE PEDRAZA, 1791}

\begin{tabular}{|c|c|c|}
\hline Vecino afectado & Bienes & $\begin{array}{l}\text { Valor } \\
\text { (pesos, reales) }\end{array}$ \\
\hline \multirow[t]{7}{*}{ Vicente Muñoz } & Por una casa aperada de un todo, hasta su embarre de diez varas. & 18 \\
\hline & Por una cabuya de rosa sembrada de maíz, yuca y ñame. & 12 \\
\hline & $\begin{array}{l}\text { Por dos docenas de gallinas que se me ahogaron con el sol, otras } \\
\text { que se extraviaron por falta de abrigo, a uno y medio reales cada una. }\end{array}$ & 4,4 \\
\hline & Por un hacha buena, apreciada en catorce reales . & 1,6 \\
\hline & Por un barranquero y una cochinita apreciados . & 2 \\
\hline & $\begin{array}{l}\text { Por dos fanegas de maíz que tenía entrojado en mi casa, apreciado } \\
\text { a ocho reales cada fanega. }\end{array}$ & 2 \\
\hline & Total & 40,2 \\
\hline \multirow{9}{*}{$\begin{array}{l}\text { Juan Gregorio } \\
\text { Meza }\end{array}$} & Por el ajuar de un rancho y casa de a ocho varas. & 2,4 \\
\hline & Por un corral o pocilga de encerrar ganado cerduno. & 2 \\
\hline & $\begin{array}{l}\text { Por cuatro puercas preñadas que se extraviaron y perdieron, apreciadas } \\
\text { en } 18 \text { reales cada una. }\end{array}$ & 9 \\
\hline & Por un pollino que me machetearon y alancearon de cuyo hecho murió . & 4 \\
\hline & Por un pilón con sus dos manos de pilar maíz que tiraron al río . & 1,2 \\
\hline & Por una novilla que se me desapareció con el motivo del alboroto. & 6 \\
\hline & $\begin{array}{l}\text { Por dos docenas de gallinas que se ahogaron con el sol y extraviaron } \\
\text { por falta de abrigo, a uno y medio reales cada una. }\end{array}$ & 4,4 \\
\hline & $\begin{array}{l}\text { Por cuatro fanegas de maíz que con el motivo de habernos acosado } \\
\text { se comieron los animales y se perdieron, a ocho reales cada fanega. }\end{array}$ & 4 \\
\hline & Total & 33,2 \\
\hline \multirow{10}{*}{$\begin{array}{l}\text { Victorino Josef } \\
\text { Artaona }\end{array}$} & $\begin{array}{l}\text { Por una casa de nueve varas empalmada, cercada y embarradas } \\
\text { con su corral de patio apreciado }\end{array}$ & 20 \\
\hline & Por dos tinaxas grandes, platos y escudillas finas, ollas grandes & \\
\hline & $\begin{array}{l}\text { y pequeñas múcuras llenas de maíz de semilla para sembrar apreciado } \\
\text { todo junto con dos gallinos echadas en huevos para sacar pollos. }\end{array}$ & 11,4 \\
\hline & $\begin{array}{l}\text { Por dos catres forrados de cuero con el motivo de la tumba de la casa } \\
\text { se hicieron pedazos apreciados en tres pesos cada uno. }\end{array}$ & 6 \\
\hline & $\begin{array}{l}\text { Por dos docenas de gallinas que con el sol se ahogaron y perdieron } \\
\text { a un y medio reales cada una. }\end{array}$ & 4,4 \\
\hline & $\begin{array}{l}\text { Por una piragua que se iba a componer para cuyo fin estaba en tierra } \\
\text { apreciada en } 20 \text { pesos. }\end{array}$ & 20 \\
\hline & $\begin{array}{l}\text { Por una piragüita que con el mismo motivo estaba como la anterior } \\
\text { para componerla apreciada en dos pesos. }\end{array}$ & 2 \\
\hline & $\begin{array}{l}\text { Por } 20 \text { cabezas de ganado ser dudo de cría y entre ellos seis capaditos } \\
\text { para engordar con nueve parideras. }\end{array}$ & 32 \\
\hline & $\begin{array}{l}\text { Por dos cabuyas de roza sembradas de maíz y yuca que con el motivo } \\
\text { de la persecución se perdieron. }\end{array}$ & 20 \\
\hline & Total & 116 \\
\hline
\end{tabular}

Fuente: Poblaciones SC 46, 6, D. 1, Representación que los vecinos de Pedraza hicieron a Pablo José Torregrosa para la fundación del sitio, 1791. AGN. 
Aun así, Torregrosa denunciaba el 27 de abril de 1792 que el alcalde Pedáneo de Cerro de San Antonio, Antonio José Vélez, con el apoderado de los vecinos del mismo sitio, don Januario Camacho, volvía a incomodar el proceso de fundación, cuestión que a más de afligirlo mostraba el total desacato de estos personajes a "las superiores órdenes de vuestra Excelencia", el virrey. Informaba que temía un nuevo atentado contra los colonos y manifestaba que él en ocasiones lo aburría el estar enviando repetidos y frecuentes informes; pero, remarcaba, lo seguía haciendo por cumplir con un fin mayor encargado por una autoridad superior buscando servir al soberano.

En definitiva, concluía Torregrosa señalando que el continuaba con el proceso de poblamiento invirtiendo su dinero en dar sustento diario a unos miserables colonos y esperaba que sus iniciativas fueran, más tarde, recompensadas con privilegios por parte del virrey. Se sentía parte de una política de gran importancia, que como ya señaló uno de sus enemigos también lo beneficiaba a él: perseguía terrenos aptos en pastos naturales para llevar allí sus mulas que usaba en el tráfico de mercancías entre el río Magdalena y la ciudad de Cartagena. Fue así como sus peticiones tuvieron respuesta desde Santafé, desde donde se ordenaba al alcalde pedáneo de la parroquia de San Antonio José Vélez que los vecinos del sitio debían acatar "esta superior disposición” y abstenerse de causar "molestia, inquietud o amenaza" a los vecinos de Pedraza y de no interferir en la nueva fundación.

\section{Pasto espiritual y agregación de los negros de San Basilio Para el fomento de la agricultura DEL SITIO DE PEDRaza}

Ya facultado Torregrosa para continuar con el proceso de poblamiento, apareció en el escenario el tema de la persona que impartiría "pasto espiritual" a los habitantes del sitio, por ello solicitó fuera enviado de la ciudad de Santa Marta un "diocesano y vice-patrono real" en conformidad con "las leyes municipales", al que se le debían pagar sus alimentos "subsistencia y demás gastos referidos y hasta que tomando más incremento de la población, pueda vivir a expensas del vecindario como es de justicia" 35 Sus ruegos fueron escuchados y en el mes de noviembre de ese año de 1792 se propuso por orden del obispo don Anselmo Fraga como reverendo a "fray Domingo Salazar" de la orden de los Agustinos Descalzos ${ }^{36}$ En ese sentido Torregrosa solicitó al virrey que aprobara dicho nombramiento que habría de servir a "ambas Magestades". Este cura se habría de encargar de la "enseñanza de la doctrina christiana y santo temor de Dios" y, de hecho, había estado ayudando a Torregrosa en el proceso de reclutar población para la nueva fundación. Para apoyar el nombramiento Torregrosa anexo a su carta enviada al virrey Espeleta, otra del mencionado cura, donde este sostenía que de ser nombrado se haría "un obsequio a la divina y humana Magestad, no menos que una obra de misericordia a estos pobres infelices, nuevos oprimidos israelitas" y, además, comparaba, de darse la aprobación, la acción del virrey con la de "aquel caudillo del pueblo de Dios" -Moisés- que al tocar "con la vara de su pronta resolución los pedernales" llevaba "satisfacción a estos sedientos pobladores" 37

\footnotetext{
${ }^{35}$ Poblaciones SC 46, 6, D. 1, Representación. AGN.

${ }^{36}$ En la ciudad de Santa Marta el 27 de noviembre de 1792 se autorizó el nombramiento de cura y se realizó consulta sobre la disponibilidad de las cajas reales para el pago de su estipendio, solicitándose además que la iglesia de Pedraza fuera dotada de alhajas y los ornamentos necesarios para su pleno funcionamiento.

${ }^{37}$ Poblaciones SC 46, 6, D. 1, Representación. AGN.
}

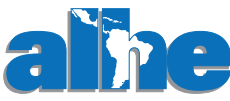


Hasta aquí no es extraño encontrar que el gobernador Astigarraga se opusiera a que se nombra a un cura en el sitio de Pedraza, y este reclamaba al virrey el 27 de noviembre de 1792 desde Santa Marta, que el nombramiento de fray Domingo Salazar se había hecho "sin previa noticia ni consentimiento del vice-real patronato que debía prestarlo para su erección”, ni con "arreglo a las leyes municipales y reales cédulas" que obligaban a que se le informara sobre el proceso 38

Para comienzos del año de 1794 Torregrosa informaba que la refundación iba por buen camino, ya que la mayoría de los vecinos se encontraba "arreglados y establecidos con sus campos de rozas de bastante atención, por sus tamaños y abundancia de frutos con que se socorren y auxilian a todos los demás pueblos inmediatos" 39 Recalcaba que en el sitio se habían establecido primero un total de 27 familias a las que se le habían agregado 33 procedentes "de los expulsados del palenque de San Basilio", para un total de 60 vecinos cabezas de familia. El hecho de llevar familias expulsadas del sitio de San Basilio, en la gobernación de Cartagena, despertó nuevamente las querellas contra Torregrosa y la fundación de Pedraza. Nuevamente Januario Camacho entra en escena enviando el mes de marzo de 1794 una carta al, para esa fecha, gobernador de Santa Marta Antonio Samper, quejándose de que al sitio se agregaran las familias de "los negros" procedentes de San Basilio de Palenque, por considerar que eran hombres "sumamente malos y cargados de todos vicios”, además de ladrones, razón por la que habían sido desterrados. El gobernador procedió a enviar una carta al virrey en fecha de abril 8 de 1794 donde daba cuenta de la querella de Camacho y de los prejuicios que se darían a "aquel vecindario con la introducción de esta mala gente para que en su vista se sirva vuestra Excelencia proveer lo que fuese de su superior agrado" 40

Fue así como el fiscal de apellido Blaya de la Audiencia de Santafé pidió información al gobernador de Cartagena sobre la destrucción del sitio de San Basilio y el desplazamiento de parte de su población a otros lugares, recibiendo contestación desde Cartagena el día 29 de julio 1794 por parte de Joaquín de Cañaveral, quien reconocía que era cierto que se había demolido el sitio como previamente el virrey había autorizado en el mes de febrero y se había procedido a distribuir a las familias en poblados que habían considerado convenientes buscando "evitar al mismo tiempo su inmediación a aquel y otros donde en lo sucesivo pudieran arrochelarse”. 41

$\mathrm{Al}$ respecto, Cañaveral señalaba sobre el tema de las familias agregadas del sitio de San Basilio que él había hablado con ellos y estos se habían comprometido agregarse al sitio de Pedraza, mostrando "la mayor obediencia, conformidad y respeto sin que hasta ahora haya tenido la menor quexa de alguno, de modo que los que se creyeron tigres, por la justa opinión que les adquirieron sus pasados excesos, se han visto después unas ovejas dóciles, humildes y sumisos a la voluntad del gobierno" 42

La conclusión fue que al contrario de lo que señalaba Januario Camacho, la población de palenque era de gran utilidad para el incremento de "la agricultura y fomento de la nueva referida población de Pedraza”. Por ello, las familias expulsadas de San Basilio que se asentaron en Pedraza pasaron de ser unos supuestos criminales a unos sujetos dóciles que podían encauzarse en un buen servicio a la sociedad, todo ello por comprometerse a cultivar sus tierras, es decir se transmutaran en la clase de los colonos. Por ello Torregrosa pidió al virrey que aprobara su traslado y agregación de estos "pobres infelices" que merecían una segunda oportunidad.

${ }^{38}$ Poblaciones SC 46, 6, D. 1, Representación. AGN.

${ }^{39}$ Poblaciones SC 46, 6, D. 1, Representación. AGN.

${ }^{40}$ Poblaciones SC 46, 6, D. 1, Representación. AGN.

${ }^{41}$ Poblaciones SC 46, 6, D. 1, Representación. AGN.

${ }^{42}$ Poblaciones SC 46, 6, D. 1, Representación. AGN. 
Por último, desde Barranca del Rey el 31 de julio de 1794 Torregrosa reconocía que sólo había podido trasladar a Pedraza 20 familias de las 33 que provenían de San Basilio, las restantes se habían ubicado en los sitios de Barranca Vieja, Mahates, Sambote y San Cayetano. Respecto a los que accedieron a quedarse señalaba que su conducta era de una "sana y sincera" docilidad, por lo que adjuntaba un concepto del fiscal Blaya dado en Santafé el 21 de agosto de 1794 donde señalaba que, según su criterio, no había ningún inconveniente en que se trasladaran algunas familias "de los negros" de San Basilio a Pedraza. Para este personaje, el voluntarismo que Josef Torregrosa le había imprimido a la empresa poblacional, conjuraba cualquier conflicto, ya que este se había caracterizado por usar "los términos más suaves que le dice su prudencia haciéndoles ver a aquellos la utilidad, que puede resultar de su aumento a beneficio del comercio y agricultura, y que, si alguno de los que ahora se agrega, fuere de genio díscolo, o perturbare la tranquilidad pública proceda a su corrección y castigo en los términos que lo erige la justicia" 43

Así, los atrevidos vecinos de San Basilio, una vez asentados en Pedraza, pasaron a convertirse en agentes productivos necesarios a los intereses de la corona, especialmente del abasto de la ciudad de Cartagena.

\section{Conclusiones}

Lo que hemos presentado en líneas anteriores constituye una parte de un trabajo mayor sobre el impacto del discurso ilustrado y la dotación de derechos corporativos a los habitantes de los llamados sitios de libres, en tiempos de Carlos III. En el camino de incrementar la productividad agropecuaria la burocracia ilustrada estableció políticas de integración y dotación, a un grupo poblacional de linaje mezclado, de derechos y deberes. Los antes censurados libres de todos los colores pasaron ahora a ser vecinos, con calidad de labradores. Esta política buscaba gestionar la aparición de un sujeto productivo llamado labrador o colono, el cual a finales del siglo xviI observaba cómo los funcionarios reales hacían suyos sus intereses, los defendían y dotaban de tierras y derechos comunales (García, 2017). De labradores se llenarían, ahora, los censos estadísticos que daban cuenta de las actividades productivas en el campo.

Si bien ceder tierras de uso comunal se enmarcó en antiguas formas jurídicas de condominio de fuente castellana, ahora, en la segunda mitad del siglo xviII el fin era otro. Aquí aparece en escena una idea de gobierno que usando elementos corporativos integraba la población y supeditaba el éxito de su política a la capacidad productiva de los nuevos ciudadanos. Sin embargo, esta política que se nutría del programa fisiócrata estuvo acompañada también de la reproducción institucional, corporativa, jurisdiccional y de un reordenamiento territorial, lo cual redundó en el fortalecimiento de la presencia del poder real en áreas periféricas que habían disfrutado durante muchos años de amplios márgenes de autonomía. Para los burócratas ilustrados fue más fácil establecer sus políticas en zonas donde las debilidades de los cabildos y las particularidades de un mestizaje menguaban la acción de intermediarios e instituciones locales.

$\mathrm{Al}$ final, la trama estudiada muestra una sincronización entre las acciones de la burocracia asentada en la Audiencia de Santafé, la aplicación de la política de acceso a la tierra para incrementar la producción agrícola y las ideas de los fisiócratas españoles. Es decir, que las ideas esbozadas por la burocracia ilustrada que rodeaba a los borbones fueron institucionalizadas por los virreyes

${ }^{43}$ Poblaciones SC 46, 6, D. 1, Representación. AGN. 
neogranadinos y refrendadas por el uso que de ella hicieron actores hasta ahora desconocidos del mundo rural neogranadino ${ }^{44}$ Incluso, en la aplicación de dicha política se menoscaba la potestad jurisdiccional de algunos agentes, en este caso el gobernador de Santa Marta.

Para concluir, no podemos perder de vista que la política económica que buscaba el crecimiento agropecuario se insertó, a una escala mayor, en esa idea moderna que buscaba -como argumenta Horst Pietschmann (1994, p. 171) - dar a los individuos facilidades para que crecieran en términos económicos, porque el crecimiento individual, del bien público o del Estado ${ }^{45}$ como se señalaba en los documentos de la época, se concebía como la suma de voluntades individuales; eso que hoy llamamos liberalismo. Conviene señalar que el uso de palabras y frases por parte del visitador real, el obispo y el capitán aguerra del sitio de Barrancas, Josef Torregrosa, buscaban arropar las órdenes dadas sobre la fundación de Pedraza de un excesivo voluntarismo, fundar poblaciones, entonces debía servir a la religión, al público y al Estado porque se lograba que unos pobres infelices tuvieran un "un gran bien tanto en lo moral, como en lo político". Así, las ideas fisiócratas encajaban y eran, en este caso, la savia que alimentaba esa concepción englobante de la sociedad, en búsqueda de la felicidad pública, por lo menos en las áreas rurales del virreinato de Nueva Granada.

\section{LISTA DE REFERENCIAS}

Andreucci, B. (2011). Labradores de frontera. La Guardia de Luján y Chivilcoy, 1780-1860. Rosario: Protohistoria.

Arcila, M. T., y Gómez, L. (2009). Libres, cimarrones y arrochelados en la frontera entre Antioquia y Cartagena, siglo XVIII. Bogotá-Medellín: Siglo del Hombre Editores/Universidad de Antioquia. Recuperado de http://www.digitaliapublishing.com/a/29632/

Astigarraga, J. (2010). André Morellet y la enseñanza de la economía en la ilustración española. La "Memoria sobre la utilidad del establecimiento de una escuela de comercio". Cuadernos de Historia Moderna, 35, 143-173.

Astigarraga, J., y Usoz, J. (2007). Una alternativa fisiócrata al Informe de Ley Agraria de Jovellanos. Revista de Historia Económica / Journal of Iberian and Latin American Economic History, 25(03), 427-458. DOI: 10.1017/S0212610900000197

Astigarraga, J., y Usoz, J. (2008). Algunas puntualizaciones en torno a la fisiocracia en la ilustración tardía española. Revista de Historia Económica/Journal of Iberian and Latin American Economic History, 26(3), 489-497. DOI: 10.1017/S0212610900000434

Bohórquez, J. (2014). Luces para la economía: libros y discursos de economía política en el Atlántico espanol durante la era de las revoluciones (Nueva Granada, 1780-1811). Bogotá: Instituto Colombiano de Antropología e Historia.

Bonil, K. (2011). Gobierno y calidad en el orden colonial: las categorías del mestizaje en la provincia de Mariquita en la segunda mitad del siglo XVIII. Bogotá: Universidad de los Andes.

Bonnett, D. (2001). De la conformación de los pueblos de indios al surgimiento de las parroquias de vecinos. El caso del Altiplano cundiboyacense. Revista de Estudios Sociales, 10, 9-19. DOI: $10.7440 /$ res 10.2001 .01

\footnotetext{
${ }^{44}$ Sobre los discursos de los ilustrados y la agricultura en el Nuevo Reino de Granada véase (Bohórquez, 2014)

${ }^{45}$ En lo que se refiere al tema del Estado en siglo XviII hacemos nuestra la definición que de este realiza Monod: "El Estado como una entidad colectiva autosostenida ligada a la persona real” (Monod, 1996, p. 19).
} 
Canedo, M. (2015). Ocupantes espontáneos y derechos por la tierra en la formación de "pueblos de españoles" (Rincón de San Pedro, Buenos Aires, 1740-1860). Quinto Sol, 19(2), 1-24. DOI: 10.19137/qs.v19i2.1047

Caro, C. (2017). Cerramientos de tierra en el siglo xviII según los despachos de Gracia del Consejo de Castilla. Hispania, 77(255), 117. DOI: 10.3989/hispania.2017.005

Celaya, Y. (2015). Arbitrio a maíces y harinas: pensamiento y ejecución en los ayuntamientos novohispanos, siglo xviII. En M. del P. Martínez, E. Sánchez y M. Souto (eds.), La fiscalidad novohispana en el imperio español: conceptualizaciones, proyectos y contradicciones (pp. 325-357). México: Instituto de Investigaciones Dr. José María Luis Mora/Universidad Nacional Autónoma de México. Recuperado de http://www.historicas.unam.mx/publicaciones/publicadigital/libros/fi scalidad_novohispana/04_12_arbitrio_maices.pdf

Colmenares, G. (1989). Relaciones e informes de los gobernantes de la Nueva Granada. Bogotá: Fondo de Promoción de la Cultura del Banco Popular.

Covarrubias, J. E. (2005). En busca del hombre útil: un estudio comparativo del utilitarismo neomercantilista en México y Europa, 1748-1833. México: Universidad Nacional Autónoma de México.

Epstein, S. R. (2009). Libertad y crecimiento: el desarrollo de los estados y de los mercados en Europa, 1300-1750. Valencia: Universitat de València.

Fals-Borda, O. (1979). Historia doble de la costa. Bogotá: C. Valencia Editores.

Friera, M. (2007). La desamortización de la propiedad de la tierra en el tránsito del antiguo régimen al liberalismo. La desamortización de Carlos $I V$. España: Fundación Foro Jovellanos del Principado de Asturias.

García, C. (ed.) (2010). Las reformas borbónicas, 1750-1808. México: Fondo de Cultura Económica.

García, C. (1986). Haciendas municipales y bienes de propios: las reformas de Carlos III. Anales de Estudios Económicos y Empresariales, 1, 89-114.

García, L. J. (2015). Demandas sociales y propiedad imperfecta en Veracruz: el impulso a la enfiteusis (1760-1811). Secuencia, 93, 28. DOI: 10.18234/secuencia.v0i93.1269

García, L. J. (2017). Unidos en un mismo cuerpo: monarquía y sociedad en un tiempo de reformas: Veracruz 1764-1810. México: El Colegio de Michoacán/Universidad Veracruzana.

Garrido, M. (1993). Reclamos y representaciones: variaciones sobre la política en el Nuevo Reino de Granada, 1770-1815. Santafé de Bogotá: Banco de la República.

Gelman, J., Llopis, E., Marichal, C., Moraes, M. I., Contreras, C. et al. (eds.). (2014). Iberoamérica y España antes de las independencias, 1700-1820: crecimiento, reformas y crisis. México: Instituto de Investigaciones Dr. José María Luis Mora/Consejo Nacional de Ciencia y Tecnología/El Colegio de México.

Guasti, N. (2013). Campomanes' civil economy and the emergence of the public sphere in Spanish Ilustración. En J. Astigarraga y J. Usoz (eds.), L'ecomie politique et la sphere publique dans le débat des lumieres (pp. 229-257). Madrid: Casa de Velázquez.

Guerrero, A. A., Pabón, S., y Ferreira, C. A. (2014). Poblamiento y economía: orígenes de los asentamientos urbanos en el nororiente colombiano durante la colonia. Bucaramanga: Universidad Industrial de Santander.

Guimerá, A. (1996). Introducción. En A. Guimerá (ed.), El reformismo borbónico: una visión interdisciplinar (pp. 9-33). Madrid: Alianza/CSIC.

Herrera, M. (2002). Ordenar para controlar: ordenamiento espacial y control político en las llanuras del Caribe y en los Andes Centrales Neogranadinos, siglo XVIII. Bogotá: Instituto Colombiano de Antropología e Historia. 
Herrera, M. (2009). Popayán: la unidad de lo diverso: territorio, población y poblamiento en la provincia de Popayán, siglo XVIII. Bogotá: Universidad de Los Andes.

Kuethe, A. J. y Andrien, K. J. (2014). The Spanish Atlantic World in the Eighteenth Century: War and the Bourbon Reforms, 1713-1796. Nueva York: Cambridge University Press. DOI: 10.1017/CB O9781107338661

Lempériere, A. (2014). El Estado en los espacios ibéricos: ċorden natural o máquina performativa? En J. Fernández (ed.), Diccionario político y social del mundo iberoamericano, Estado (vol. 3, pp. 1535). Madrid: Universidad del País Vasco/Iberconceptos.

Lynch, J. (1991). El siglo XVIII: historia de España. Barcelona: Crítica.

McFarlane, A. (1997). Colombia antes de la independencia: economía, sociedad y política bajo el dominio borbón. Bogotá: Banco de la República/El Áncora.

Meisel, A. (1980). Esclavitud, mestizaje y haciendas en la Provincia de Cartagena 1533-1851. En G. Bell y R. de la Pedraja (eds.), El Caribe colombiano. Selección de textos históricos (pp. 69-137). Barranquilla: Uninorte.

Monod, P. (1996). Estado, nación y monarquía en el siglo XviII: visión comparativa. En C. Russell, J. A. Gallego, y P. García (eds.), Las monarquías del antiguo régimen, żmonarquías compuestas? (pp. 11-30). Madrid: Complutense.

Mora, G. (1993). Poblamiento y sociedad en el bajo Magdalena durante la segunda mitad del siglo XviII. Anuario Colombiano de Historia Social y de la Cultura, 21, 40-62.

O’Byrne, A. (2013). El desabastecimiento de géneros agrícolas en la Provincia de Cartagena de Indias a fines del periodo colonial. Historia Crítica, 50, 59-78. DOI: 10.7440/histcrit50.2013.03

Olavide, P. de. (1768). Informe al Consejo sobre la Ley Agraria [Biblioteca virtual]. Recuperado 23 de enero de 2019, de http://www.cervantesvirtual.com/s3/BVMC_OBRAS/fee/4ca/be8/2 b1/11d/fac/c70/021/85c/e60/64/mimes/fee4cabe-82b1-11df-acc7-002185ce6064_4.htm

Perdices, L. (1993). Pablo de Olavide (1725-1803), el ilustrado. Madrid: Complutense.

Peredo, D. (1971). Noticia historial de la provincia de Cartagena de las Indias, año 1772. Por Diego de Peredo. Anuario Colombiano de Historia Social y de la Cultura, 6-7, 119-154.

Pietschmann, H. (1994). Un testimonio del impacto del reformismo borbónico en Nueva España: la representación del intendente de Puebla de los Ángeles de 27 de junio de 1792. Jahrbuch für Geschichte Lateinamerikas, 31(1), 1-38. DOI: 10.7788/jbla-1994-0103

Pinto, J. (2016). El reformismo fiscal borbónico en la Nueva Granada, balance y perspectivas. Historia Caribe, 11(29), 53-82. DOI: 10.15648/hc.29.2016.4

Real Academia Española (2012). Diccionario de Autoridades (1726-1739) [tt. 2-4]. Madrid: Autor. Recuperado de http://web.frl.es/DA.html

Rodríguez, P. (1764). Respuesta fiscal sobre abolir la tasa y establecer el comercio de granos. Madrid: Imprenta de D. Antonio de Sancha. Recuperado de http://bdh-rd.bne.es/viewer.vm?id=0000086 013ypage=1

Rodríguez, P. (1774). Discurso sobre el fomento de la industria popular. Madrid: Imprenta de D. Antonio de Sancha. Recuperado de http://bdh-rd.bne.es/viewer.vm?id=0000094201ypage=1

Rodríguez, E. A. (2014). “Derriben las casas para que no les quede esperanza de restituirse a ellas”. Erección de la parroquia de Sogamoso, 1777-1810. Fronteras de la historia, 19(2), 96-120. DOI: $10.22380 / 2027468826$ 
Rojas, B. (2007). Los privilegios como articulación del cuerpo político. Nueva España, 17501821. En B. Rojas (ed.), Cuerpo político y pluralidad de derechos: los privilegios de las corporaciones novohispanas (pp. 45-84). México: Centro de Investigación y Docencia Económicas/Instituto de Investigaciones Dr. José María Luis Mora.

Sánchez, E. (2010). Una modernización conservadora: el reformismo borbónico y su impacto sobre la economía, la fiscalidad y las instituciones. En C. García y I. Marván (eds.), Las reformas borbónicas, 1750-1808 (pp. 288-336). México: Fondo de Cultura Económica.

Sánchez, F. (1988). Demanda de tierras para roturar en España durante el siglo XviII. Agricultura $y$ Sociedad, 49, 393-465.

Sánchez, H. R. (2008). Esclavitud, zambaje, "rochelas” y otros excesos en la población libre de las gobernaciones de Santa Marta y Cartagena, 1600-1800. En A. R. Portugal, E. Pérez, G. Saldarriaga, H. P. Pérez, H. Clavijo y Y. A. Chicangana-Bayona (eds.), Historia, cultura y sociedad colonial, siglos XVI-XVIII (pp. 127-157). Medellín: La Carreta Historia.

Sánchez, H. R. (2015). De arrochelados a vecinos: reformismo borbónico e integración política en las gobernaciones de Santa Marta y Cartagena, Nuevo Reino de Granada, 1740-1810. Revista de Indias, 75(264), 457-488. DOI: 10.3989/revindias.2015.015

Sánchez, H. R. (2016). Reformismo borbónico, tierras comunales y labradores en la gobernación de Santa Marta, 1750-1810. En R. Román (ed.), Economía del Caribe colombiano y construcción de nación (1770-1930) (pp. 19-57). Bogotá: Universidad Nacional de Colombia.

Tovar, H. (1980). Grandes empresas agrícolas y ganaderas: su desarrollo en el siglo XVIII. Bogotá: Universidad Nacional de Colombia/CIEC.

Usoz, J. (2008). La política ilustrada y el libre comercio de granos: las 'Reflexiones económicopolíticas' (1768) de Tomás Anzano. Historia Agraria: Revista de Agricultura e Historia Rural, 46, 21-51.

Ward, B. (1782). Proyecto economico, en que se proponen varias providencias, dirigidas á promover los intereses de España, con los medios y fondos necesarios para su plantificación; escrito en el año de 1762 por D. Bernardo Ward. España: D. Joachin Ibarra, Impresor de Cámara de S. M.

Windler, C. (1997). Élites locales, señores, reformistas: redes clientelares y Monarquía hacia finales del Antiguo régimen. Cordoba-Sevilla: Universidad de Cordoba/Universidad de Sevilla. 